(2) Open Access Full Text Article

ORIGINAL RESEARCH

\title{
Investigating the effect of physical games on the memory and attention of the elderly in adult day-care centers in Babol and Amol
}

This article was published in the following Dove Press journal:

Clinical Interventions in Aging

Maryam Hedayati ${ }^{1,2}$

Shima Sum ${ }^{2}$

Seyed Reza Hosseini ${ }^{3}$

Mahbobeh Faramarzi ${ }^{3}$

Samaneh Pourhadi ${ }^{3}$

'Student Research Committee, Babol University of Medical Sciences, Babol, Iran; ${ }^{2}$ Department of Social Medicines, Babol University of Medical Sciences, Babol, Mazandaran, Iran; ${ }^{3}$ Social

Determinants of Health (SDH) Research Centre, Health Research Institute, Babol University of Medical Sciences, Babol,

Mazandaran, Iran
Correspondence: Samaneh Pourhadi Department of Social Medicine, Babol University of Medical Sciences,

Ganjafrooz Street, Babol 47I7647745, Iran

Tel $+98 \mid 1321995916$

Fax $+98 \quad 1132208233$

Email Samaneh.Pourhadi@gmail.com
Background: Physical activity is a behavioral strategy that increases general (public) health, including the mental performance of individuals. The goal of this study was to investigate the effect of group physical games on cognitive performance (memory, attention) of old people in adult day-care centers.

Methods: In this quasi-experimental study, 50 elderly people (aged $>60$ years) were selected from two adult day-care centers using available sampling and divided into two groups: control and intervention. As approval was received from the Babol Hamrah Salamat adult day-care center to modify the design of the center's yard, this center was selected to conduct an intervention program. The intervention group received a physical activity program twice a week for 6 weeks. Questionnaires that were used for collecting data included demographic questions, a standard questionnaire for daily activities of living, and a shortterm test, the Abbreviated Mental Test Score. Cognitive function was assessed with the Wechsler Memory Scale (WMS) (Form A), before and after the intervention. Statistical analysis of normal variables was performed using independent and paired $t$-tests and in nonstandard cases with Mann-Whitney and Wilcoxon non-parametric tests at a significance level of $P<0.05$, using SPSS software (version 22).

Results: Statistical analysis showed that the scores of the subjects in the intervention group, compared to the control group, had significantly improved. The calculated mean differences in the intervention groupwere, for memory function $d=8.4 \pm 3.3(P=0.001)$, and for attention and concentration $d=4.18 \pm 2.38(P<0.001)$ (WMS). This level of change in the intervention group was significant.

Conclusion: The results of this study showed that a physical exercise program can improve the memory and attention/concentration of the elderly. Therefore, it seems that such activities are a useful method for maintaining cognitive function.

Keywords: aging, cognition, Wechsler test, physical games, adult day-care center

\section{Introduction}

Population aging is a globally pandemic phenomenon coming about as a result of improvements in living conditions and healthcare in many societies. Demographic projections indicate a relatively certain trend in the continuation of aging and longevity during the twenty-first century. ${ }^{1,2}$ Based on predictions by statistical indices, by 2050 , the elderly will constitute $13.7 \%$ of the world's population. By the same year, $17.6 \%$ of the Iranian population will be elderly. ${ }^{3}$ 
As a period in human life, old age is accompanied by biological changes in which physical and cognitive abilities suffer a considerable decline as a consequence of a gradual drop in the performance of body systems. ${ }^{4}$ One of the chronic disorders of old age which is currently attracting the attention of a lot of specialists is cognition disorder, which threatens the independence and quality of life of the elderly. ${ }^{5-7}$ The prevalences of cognition disorders among Swedish and German elderly are $4.5 \%{ }^{8}$ and $7.7 \%,{ }^{9}$ respectively. For American elderly, the same incidence is $4.9 \%$ in 65 -year-olds and higher, reaching $9.6 \%$ for the elderly older than 85 years. ${ }^{10}$ This percentage for Iranian elderly has been reported to be $18.3 \%{ }^{11}$ Studies have shown that about $5 \%$ of 60 -year-olds suffer from pronounced cognition disorder, and this percentage reaches more than $25 \%$ among 80 -year-olds and higher. ${ }^{12}$ Thus, maintaining and improving cognitive performance among the elderly is gaining a special emphasis, and solutions are being sought to prevent cognition disorder in the first place, and keep it from progressing when it has occurred, or to reduce the speed of its progression and to restore the person's lost abilities to some extent. ${ }^{13}$

According to studies by psychologists and other scholars, physical activity is one behavioral strategy that can contribute to improvements in general well-being, including mental performance. ${ }^{14}$ Studies dealing with the effects of exercise and physical activities on cognitive performance improvement have shown positive results in this regard. ${ }^{15,16}$ These studies have been conducted on different age groups, including the elderly. Several mechanisms have been presented to describe the relationship between physical activity and cognitive performance. According to the results from one review study, physical features in the elderly can be predictors of their health status, and a lower physical strength is associated with lower cognitive performance. ${ }^{17}$ Performing physical activities has shown significant cognitive benefits in the elderly, with or without cognition disorders. ${ }^{18}$ Improvements in executive performance, attention, cognitive speed, working memory and implicit memory have been observed among the elderly following physical activity. ${ }^{19}$ Longitudinal studies conducted in this area support the possibility of a lasting effect of physical activity on cognitive performance and delaying the occurrence of cognitive performance decline with age. ${ }^{20}$ Studies use a variety of interventions to achieve physical activity. Physical games are a fun form of physical activity that are performed as a means to induce joy and enhance cognitive performance. Playing is a skill to enjoy the tasks at hand, through which the sense of urgency in life is temporarily masked. Performed in the right location, playing can accommodate the experiencing of a wide variety of strength and motor games, the stimulation of the five senses, social interactions, group or individual play, and competition and discourse among peers. ${ }^{21}$

Despite all the aforementioned physical and mental benefits, lack of movement is quite prevalent among the elderly. ${ }^{22}$ Studies have shown that only $13.7 \%$ of the elderly are engaged in physical activities. ${ }^{23}$ In Iran, $68 \%$ of individuals above the age of 60 do not participate in any kind of physical activity during the week. ${ }^{24}$ It is not easy to encourage the elderly to be more active. It has been reported that costs or lack of money, insufficient awareness of the benefits of physical activities, distance from gyms, transportation restrictions and dependence on others for getting around, and lack of time are among the main factors keeping the elderly from taking part in physical activities; and that gaining health, maintaining and improving physical fitness, pleasure and joy, social interactions, and controlling stress are among the top motivators for the elderly to engage in physical activities. ${ }^{22}$ Mouton et al made use of games to improve motion and physical activities in the elderly, and they observed that the elderly would gradually engage in exercise sessions with more independence and enthusiasm. ${ }^{25}$ Thus, physical activities that are enjoyable and are performed in a group can act as an incentive to encourage the elderly to regularly participate in them. Incorporating interactive computer games has also been studied, but they did not produce superior results to those of exercise interventions, nor were they suitable for every senior, especially considering that some of them come from traditional backgrounds. ${ }^{26}$

Therefore, considering the increase in the Iranian elderly population, the existence of a relationship between physical activity and cognitive performance, and the lack of research in the field of incorporating physical games, the present study has been conducted with the aim of investigating the effectiveness of such games in improving elderly people's memory and attention. Creating a suitable environment in an open and accessible space, and implementing the activities in the form of games can encourage the elderly to take part, cultivate more friendly bonds with the younger generations, pave the ground for the elderly to benefit from outdoor physical activities to boost their attention and memory, exhibit the degree of the effectiveness of such games, and encourage further studies in this field. 


\section{Methods}

\section{Study participants and procedure}

The present study was a quasi-experimental design, in which the intended variables were evaluated in the control and intervention groups using pre-test and post-test. The statistical population of the study comprised the elderly at adult day-care centers in the province of Mazandaran, Iran, and the study sample, based on convenience sampling, comprised 50 senior citizens from two adult day-care centers in the cities of Amol and Babol, of whom 25 participants from the Babol Hamrah Salamat adult day-care center were allocated to the intervention group and 25 from the Amol Javidan adult day-care center formed the control group of this program. The Babol adult day-care center was chosen for the intervention program because it had accepted the plan to make changes to the center's yard so that it could accommodate the implementation of the intervention program. Independent seniors with activity of daily living (ADL) scores $>10$ and Abbreviated Mental Test Score (AMTS) $>6$ in the $60-85$-year age group participated in this study. Individuals who had comorbidities with medical prohibitions or intense sight and hearing impairments, and those who were not

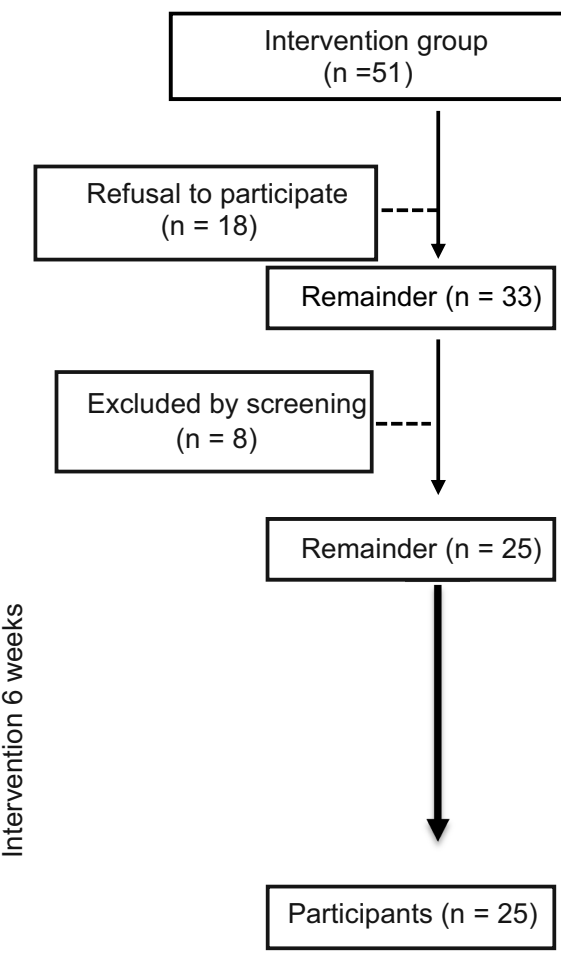

willing to participate or were absent from the study for more than two sessions, were excluded from the study. A flowchart of the study is presented in Figure 1.

To observe the study ethics, in addition to obtaining the written informed consent of all subjects, it was made clear to the individuals that the study results are solely for scientific research purposes and will be published in collective form and without mentioning the names of individuals. They were also told that participation in the study is entirely optional. To show appreciation to the participants in the control group, educational pamphlets on spiritual health were distributed among them and they were given two sessions of self-care training.

This study was conducted in accordance with the Declaration of Helsinki. The study was carried out following approval from the Ethics Committee of the Babol University of Medical Sciences and obtaining written permission from the university. The program has been registered at the Iranian Registry of Clinical Trials (IRCT) with the ID 26706.

The intervention in this study was executed outdoors in the form of playing physical games in the yard. The design pattern of this space was modeled after the Iranian Education's Hayat Pooya (dynamic yard) program, which

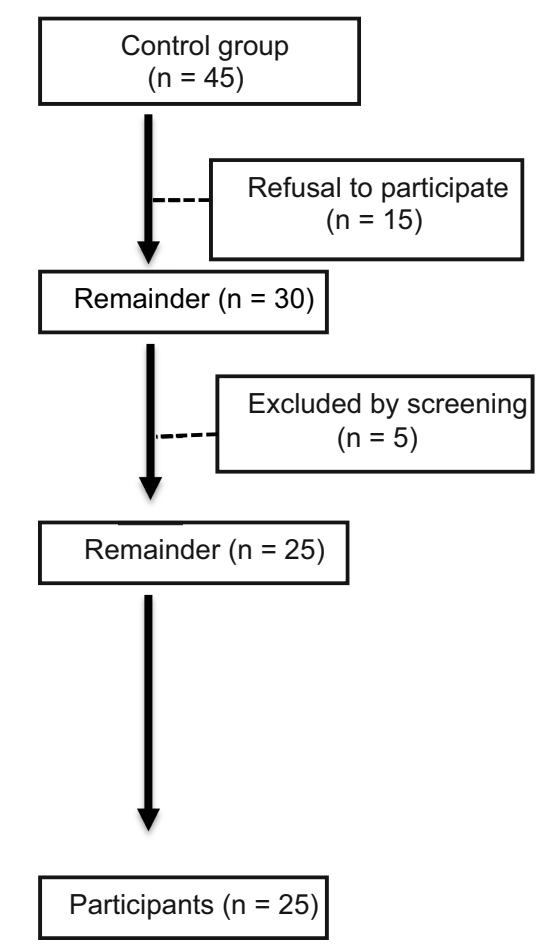

Figure I Flowchart of the study. 
has been implemented across some schools since 2012. ${ }^{27}$ In the Hayat Pooya scheme, simple and feasible methods such as drawing shapes and tables and installing safe and lightweight equipment in the minimum possible space are used to make the yard space and surroundings more fun and appealing, so that it will accommodate mental and physical activities during free time. Following the guidance of an advisory team and a sports physiology expert, the yard of the care center in Babol was adjusted based on the above-mentioned plan in such a way that it was suitable for the elderly. Some patterns were drawn on the walls and others on the ground, and they were then painted using warm and cheerful colors (Figure 2).

Hula hoops were used as moving targets, and foam, balls, and walnuts were among the other tools used in the intervention. The selected executive games were implemented at their own allocated stations. To further adjust to the conditions, the performance of $50 \%$ of the elderly on each exercise was chosen as the criterion for successful play. Thus, two pilot sessions were held to perform these group physical games based on the capabilities of the senior participants, and some of these allocated stations were selected. The implementations of some of the game stations were also adjusted to further accommodate the conditions. The games protocol included boosting focus, memory, balance, interaction, and joy, executed in the forms of skill board games, and ball throws and walnut throws for scores. The introductory stage was held in one session at the adult day-care center, during which the subjects were taught how to play the games and perform the exercises. Following that, these games and workouts were performed twice a week under the supervision of the program coach and the researcher.

Eight stations had been designed and adjusted for the execution of the intervention. At the first station, the elderly, based on which zone on the workout ring they were standing in, performed the workout assigned to that zone so that the rest would follow suit. The second station was the skills board,
A

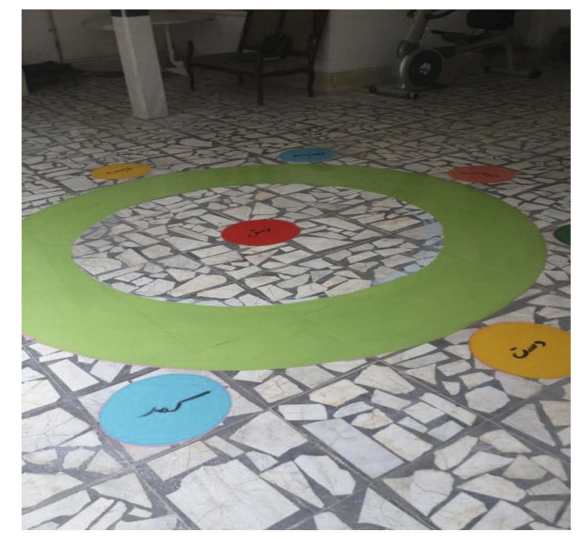

C

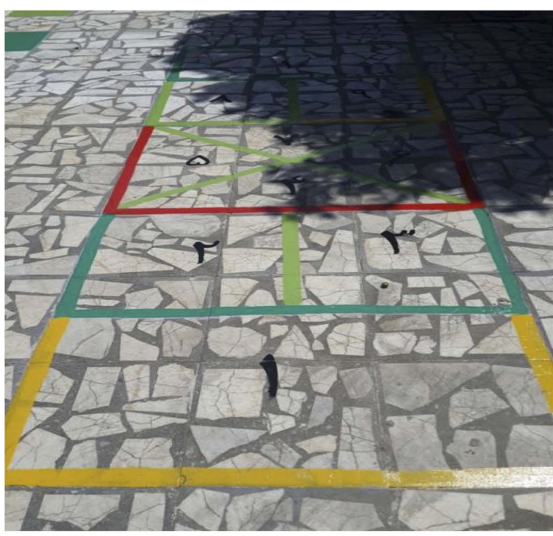

B

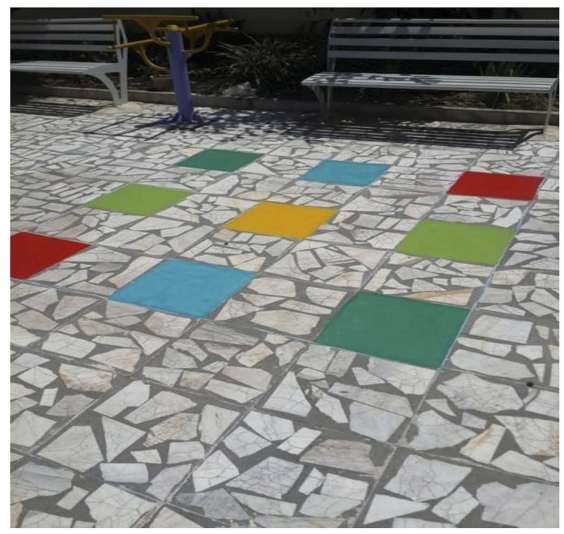

D

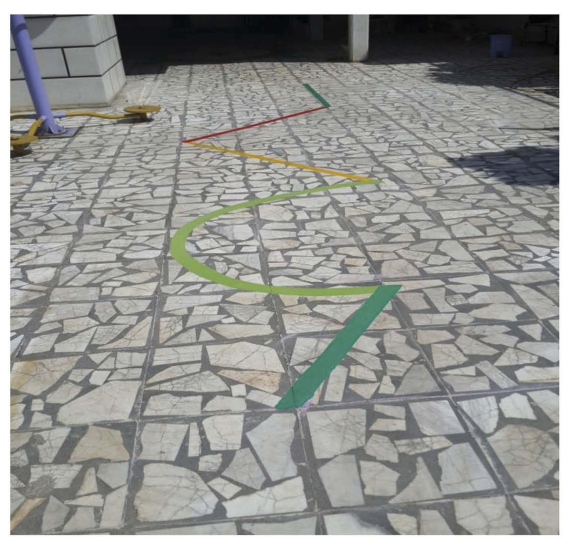

Figure 2 Designs of some stations.

Notes: (A) Warm up station (elderly perform assignment according to the zone they stand on the workout ring). (B) Tic-tac-toe station: Two groups of elderly are placed on both sides of the table. (C) Hopscotch station (modified to walking through the drawn diagram on the ground for elderly). (D) Motion activity station (elderly walk on the pass according the cards). 
where the participants were given scores based on which of the three areas their thrown ball hit. At the third station, scores were given for throwing the ball through the rolling hula hoops. The fourth station was called the motion activity station, at which the elderly would either zigzag or walk straight along the designed path based on the prompt card they had picked and the training they had received. The fifth and sixth stations reminded the elderly of their own childhood and teenage years' play, and they showed a great deal of enthusiasm about these. At the fifth station, the participants would throw walnuts, aiming to hit the $10-\mathrm{cm}$-diameter hole provisioned in the ground. At the sixth station, they would navigate through a diagram drawn on the ground. The move was originally done by hopping along, but owing to the elderly's physical considerations, walking was specified as the means of navigation. The seventh station was for tic-tac-toe, which was played in a group. Hitting the target areas on the wall by throwing balls was the game for the last station.

The subjects in the intervention group participated in 12 sessions of 75-90 minutes each. Each session consisted of three parts. First, the subjects were instructed to warm up for 10-15 minutes. Then, they would execute the relevant physical moves at the stations. Finally, they would stretch for 10 minutes to cool down. After the completion of the physical activities, the cognitive status of the elderly subjects was gauged again based on the introduced tools to determine their attention and memory status. No intervention was carried out in the control group.

The costs of intervening in the yard of the adult daycare center, estimated at 21,600,000 Iranian Rial (equivalent to 513 USD), divided into infrastructure and professional costs, are as follows:

- sports physiology expert (four sessions for the design of sports games, two sessions for the pilot trials, and the 12 intervention sessions): 6,000,000 Iranian Rial (142.50 USD)

- drawing the designing stations in the yard: $3,000,000$ Iranian Rial (71.25 USD)

- painting, including labor and seven buckets of paint (white, black, blue, red, etc): 4,000,000 Iranian Rial (95 USD)

- sporting goods, including three balls and three loops: 1,600,000 Iranian Rial (38 USD)

- cleaning and catering during the intervention: 7,000,000 Iranian Rial (166.25 USD).

\section{Questionnaires}

For the purposes of data collection, the demographic information questionnaire (created by the researcher), the ADL questionnaire, and the AMTS were filled out only in the pre-test stage and as the criterion for inclusion in the study. The ADL questionnaire is used to determine the daily physical activity status, with a validity of 0.82 , a reliability of 0.76 , and Cronbach's alpha above $0.75 .^{28}$ The AMTS questionnaire was used to screen the elderly in terms of cognition; the results from a study on test standardization conducted by Foroughan et al in 2017 in Iran showed that it has desirable credibility and reliability ( $\alpha=0.90 .5$ ) and the suitable cut-off point for this scale was determined to be 6 using the receiver operating characteristics curve to differentiate individuals with normal cognitive status from older people with mild cognitive impairment. The sensitivity of this test at this cut-off point is $99 \%$ and its specificity is $85 \%$, and it has the advantage of not being dependent on the subject's educational level. ${ }^{29}$

To determine the general status of the elderly people's memory, the A form of the Wechsler Memory Scale (WMS) test was used pre- and post-intervention. The WMS form A (WMS-I A) includes seven subtests: personal awareness of daily and personal affairs, navigation, mental control, logical memory, repetition of digits, visual memory, and a test of learning association. The raw scores from the subscales are added up and, following correction, are converted into the memory quotient. Then, based on the memory quotient score, the subject's memory status is determined. The higher the score, the better their memory. ${ }^{30}$ The primary data from the subjects' performance were statistically analyzed as follows. To obtain these scores and combined indices (verbal memory, visual memory, general memory, working memory, attention, and focus), the raw scores from the subtests were combined together and taken into consideration using the following method (with the score range of the subsets shown in parentheses): ${ }^{31}$

- verbal memory combination (0-44): logical memory subtest + association of word pairs

- visual memory (0-16): picture memory

- general memory combination (0-60): verbal memory + visual memory

- working memory (0-15): digit span tasks (forward and backward)

- attention/focus combination (0-40): mental control + digit span + visual memory span 
- total memory (0-95): logical memory (auditory memory) + digit span + visual memory span + association of wordpairs + general information + orientation to time and place + mental control.

All questionnaires were completed by the researcher (first author).

The distribution status of the data from the study was determined based on the Kolmogorov-Smirnov test. Accordingly, the independent $t$-test and the paired $t$-test were used for the variables with a normal distribution. The Mann-Whitney and Wilcoxon tests were used for nonparametric variables of the independent and dependent groups, respectively. The results were considered statistically significant below the threshold of 0.05 . The normal data in this study include the pre- and post-test general memory, the pre-test visual memory, and the post-test attention/focus, while the non-parametric findings are the pre-test attention/focus, the post-test visual memory, the pre- and post-test working memory, and the quality of life. The analyses were performed using SPSS version 22 software.
Our data will be available in SPSS format until about 1 year after paper publication, along with information about the variables in the manuscript. No other studyrelated documents are available.

\section{Results}

The mean \pm SD age of the participants in this study was $70.6 \pm 7$ years, with the youngest participant being 61 and the oldest 83 years old. Most of the elderly were either illiterate $(26 \%)$ or had received primary education (44\%) (Table 1). The data were recorded in two stages for both the exercise and control groups. That is, first at the beginning of the study and prior to the intervention, and then immediately after the end of the intervention, WMS questionnaires were filled out for the participants.

According to Table 1, the two groups of control and intervention were similar in demographic variables. Based on the results of the chi-squared test, they did not show any significant differences $(P<0.05)$.

In the investigation on the impact of games on memory, based on the A form of the WMS, the findings showed that performing these games caused significant changes in

Table I Demographic characteristics of subjects in the control and intervention groups

\begin{tabular}{|c|c|c|c|c|}
\hline \multicolumn{2}{|l|}{ Variables } & $\begin{array}{l}\text { Intervention group } \\
\text { Frequency (\%) }\end{array}$ & \multirow{2}{*}{$\begin{array}{l}\text { Control group } \\
\text { Frequency (\%) }\end{array}$} & $\begin{array}{l}\text { Asymp. sig. (2-sided) } \\
\text { (Pearson chi-square) }\end{array}$ \\
\hline & & & & \\
\hline Gender & $\begin{array}{l}\text { Male } \\
\text { Female }\end{array}$ & $\begin{array}{l}3(12) \\
22(88)\end{array}$ & $\begin{array}{l}\text { I (4) } \\
24(96)\end{array}$ & 0.297 \\
\hline Age group (years) & $\begin{array}{l}60<\text { Age } \leq 65 \\
65<\text { Age } \leq 75 \\
75<\text { Age } \leq 85\end{array}$ & $\begin{array}{l}6(24) \\
15(60) \\
4(16)\end{array}$ & $\begin{array}{l}8(32) \\
7(28) \\
10(40)\end{array}$ & 0.056 \\
\hline Education & $\begin{array}{l}\text { Illiterate } \\
\text { Elementary } \\
\text { High school and higher }\end{array}$ & $\begin{array}{l}4(16) \\
10(40) \\
11(44)\end{array}$ & $\begin{array}{l}9(36) \\
12(48) \\
4(16)\end{array}$ & 0.068 \\
\hline Marital status & $\begin{array}{l}\text { Married } \\
\text { Single } \\
\text { Widowed }\end{array}$ & $\begin{array}{l}15(60) \\
3(12) \\
7(28)\end{array}$ & $\begin{array}{l}9(36) \\
I(4) \\
15(60)\end{array}$ & 0.067 \\
\hline Living arrangements & $\begin{array}{l}\text { Living alone } \\
\text { Living with husband/wife or children }\end{array}$ & $\begin{array}{l}5(20) \\
20(80)\end{array}$ & $\begin{array}{l}\text { II (44) } \\
\text { I4 (56) }\end{array}$ & 0.69 \\
\hline Previous job & $\begin{array}{l}\text { Housewife } \\
\text { Employee } \\
\text { Unemployed }\end{array}$ & $\begin{array}{l}\text { I4 (56) } \\
5(20) \\
6(24)\end{array}$ & $\begin{array}{l}18(72) \\
4(16) \\
3(12)\end{array}$ & 0.447 \\
\hline Income & $\begin{array}{l}\text { Low } \\
\text { Medium } \\
\text { High }\end{array}$ & $\begin{array}{l}7(28) \\
12(48) \\
6(24)\end{array}$ & $\begin{array}{l}10(40) \\
13(52) \\
2(8)\end{array}$ & 0.277 \\
\hline
\end{tabular}


Table 2 Comparison of the levels of cognitive performance before and after the physical games in the intervention group

\begin{tabular}{|c|c|c|c|c|c|c|}
\hline & & $\begin{array}{l}\text { Total } \\
\text { memory }\end{array}$ & $\begin{array}{l}\text { Visual } \\
\text { memory }\end{array}$ & $\begin{array}{l}\text { Verbal } \\
\text { memory }\end{array}$ & $\begin{array}{l}\text { Working } \\
\text { memory }\end{array}$ & Attention \\
\hline $\begin{array}{l}\text { Intervention } \\
\text { group }\end{array}$ & $\begin{array}{l}\text { Pre-intervention } \\
\text { Post-intervention } \\
P^{*} \\
\text { Difference }\end{array}$ & $\begin{array}{l}48.44 \pm 7.83 \\
56.84 \pm 9.10 \\
<0.001 \\
8.4 \pm 3.30\end{array}$ & $\begin{array}{l}7.08 \pm 2.78 \\
9.50 \pm 2.80 \\
<0.001 \\
2.42 \pm 1.90\end{array}$ & $\begin{array}{l}\mid 8.76 \pm 4.10 \\
22.94 \pm 4.43 \\
<0.00 \mid \\
4 .|8 \pm 2.7|\end{array}$ & $\begin{array}{l}7.76 \pm 1.05 \\
8.60 \pm 1.19 \\
<0.001 \\
0.84 \pm 0.98\end{array}$ & $\begin{array}{l}19.48 \pm 4.09 \\
23.66 \pm 4.62 \\
<0.001 \\
4.18 \pm 2.38\end{array}$ \\
\hline
\end{tabular}

Notes: Data are presented as mean \pm SD

*Paired-samples $t$-test $(P<0.05)$.

Table 3 Comparison of the levels of cognitive performance before and after the physical games in the control group

\begin{tabular}{|l|l|l|l|l|l|l|}
\hline & & Total memory & Visual memory & Verbal memory & Working memory & Attention \\
\hline Control group & Pre-test & $39.44 \pm 9.18$ & $5 \pm 2.44$ & $16.80 \pm 3.73$ & $6.48 \pm 1.71$ & $14.24 \pm 5.10$ \\
& Post-test & $38.80 \pm 9.43$ & $4.92 \pm 3.31$ & $16.44 \pm 3.29$ & $6.56 \pm 1.60$ & $14.08 \pm 5.67$ \\
& $P^{*}$ & 0.077 & 0.683 & 0.214 & 0.774 & 0.565 \\
& Difference & $-0.64 \pm 1.72$ & $-0.8 \pm 1.22$ & $1.41 \pm 0.36$ & $1.18 \pm 0.80$ & $1.65 \pm 0.16$ \\
\hline
\end{tabular}

Notes: Data are presented as mean \pm SD.

*Total memory and verbal memory were compared with the paired-samples $t$-test, and visual memory, working memory, and attention with the Wilcoxon test $(P<0.05)$.

Table 4 Comparison of levels of change between the intervention group and the control group

\begin{tabular}{|l|l|l|l|l|l|l|}
\hline & & Total memory & Visual memory & Verbal memory & Working memory & Attention \\
\hline Intervention group & Difference & $8.4 \pm 3.30$ & $2.42 \pm 1.90$ & $4.18 \pm 2.71$ & $0.84 \pm 0.98$ & $4.18 \pm 2.38$ \\
Control group & Difference & $-0.64 \pm 1.72$ & $-0.8 \pm 1.22$ & $1.41 \pm 0.36$ & $1.18 \pm 0.80$ & $1.65 \pm 0.16$ \\
& $p^{*}$ & 0.001 & $<0.001$ & $<0.001$ & 0.003 & $<0.001$ \\
\hline
\end{tabular}

Notes: Data are presented as mean \pm SD.

*Mann-Whitney test $(P<0.05)$.

the general memory scores and the combined indices $(P<0.05)$. As shown in Table 2, the mean raw score for memory in the exercise group was $44.48 \pm 7.83$ in the pre-test, while after the program, this mean changed to $56.84 \pm 9.10$.

The mean raw score for memory in the control group was $39.44 \pm 9.18$ in the pre-test, while after the program, this changed to $38.80 \pm 9.43$ (Table 3 ).

The findings from examining the scores in the two stages, before and after intervention, showed that the changes in the intervention group were significant and positive, while no significant change was seen in the control group. The difference in changes between the two groups was also significant $(P<0.05)$ (Table 4$)$.

\section{Discussion}

Based on the theoretical foundations of this program, some exercise and physical activity interventions can cause improvements in cognitive processes such as memory and attention. Widespread and increasing investigations are underway around the world to examine the impact of physical activity on cognitive performance. The exercises incorporated in this intervention aimed at increasing physical activity and improving mental power, and consisted of a combination of physical and mental activities presented to the elderly in the form of games.

The results from the present study showed that executing these games influenced the cognitive performance of the elderly in the intervention group, so much so that significant changes were observed in these seniors in terms of improvements in general memory, visual memory, verbal memory, and attention compared to before playing these games and compared to the control group. Improvements in working memory were also confirmed, but at a lower level than for the other indices. In the control group, no index changed significantly. It was also obvious that the elderly showed increasing willingness to participate in the intervention group's games.

Several studies with the same stance have investigated the impact of physical activity and exercise on cognitive 
performance in general or on its components, such as memory, attention, and executive performance. Comparison of our findings with those of other studies shows that someof their findings are consistent with ours, while others are not.

de Asteasu et al, in studying some clinical trials, and Zhu et al, in a meta-analysis, with consistent results, confirmed the contribution of physical activity in combined and compound formats in improving cognition and slowing down the trend toward cognitive decline in old age. ${ }^{32,33}$ Law et al concluded that these kinds of interventions can have effects on both the elderly with and those without cognitive disorders. ${ }^{18}$ In this regard, Busse believes that single-component exercises are suitable for seniors with cognition problems, while compound ones are suitable options for the elderly who do not have cognition problems. ${ }^{19}$ On the other hand, the results from the present study are inconsistent with the findings by Legault et al, ${ }^{34}$ Barnes et al, ${ }^{35}$ and Broe et al. ${ }^{36}$ In Legault's and Barnes's opinions, despite an improvement in cognitive performance, no significant difference was observed between intervention groups, and the degree of involvement on the part of the elderly and the intensity of the activities are stronger influences than the type of activity. It is possible that the elderly in these two studies did not feel motivated enough to engage in the intervention sessions. The present study overcame this challenge by incorporating game-oriented activities in the intervention. Furthermore, a study on middle-aged people found that even mild and medium-intensity physical activities contribute to improvements in cognitive performance and the protection of brain in old age. In a follow-up on a 3-year study conducted in descriptive post-event form on 327 seniors, Broe et al reported no significant relation between physical activity and a reduction in Alzheimer's disease and dementia in the elderly. ${ }^{36}$ It is possible that the reasons for inconsistencies with the present study stem from differences in the method of execution. The study by Broe et al study was conducted in questionnaire and post-event format, and several factors, such as the type of exercise and environmental factors, were out of the researchers' control. But the present study was in quasi-experimental format and was conducted at an adult day-care center and under supervision, so there was a better chance of controlling the influencing factors. Also, the presence of a coach who was a sports physiology expert helped the participants to carry out the activities at a desirable level. It seems that the intervention duration, the type and intensity of the exercises, the volume and type of the sample, and the tools used for measuring the results are factors that can justify these differences. On the other hand, it should be mentioned here that the matching was carried out only between groups, and not individually. Because of the small sample size, group matching may not have enough power. So, a lower level of education and a higher age in the control group could affect our results.

The belief in the positive effects of different exercises on brain performance and delaying the onset of dementia in old age has also brought about comparative studies between different types of exercises. Investigating the effect of different types of activities, such as strength, balance, and cardiovascular training, on the cognitive performance of Italian seniors, Iuliano et al attribute the highest positive effect to cardiovascular training, which includes aerobic workouts. ${ }^{37}$ In Iran, a comparison was carried out on the degree of effect of Pilates and aerobics, showing that both contribute to improvements in cognitive variables but Pilates does better than aerobics in this regard. ${ }^{38}$ In the present study, too, exercises were designed for the relevant stations with the aim of boosting memory and attention; and focus, precision, and control were the important principles taken into consideration in implementing these stations. It seems that performing activities that require the incorporation of cognitive components can better contribute to cognitive improvements in the elderly.

In this study, positive and significant changes in memory occurred following the intervention, as assessed through memory subscales such as working, verbal, and visual memories. The results from the study by Eggenberger et al showed retention and improvement in attention, working, visual, and implicit memories, and processing speed. ${ }^{39}$ Vaughan et al achieved similar results through a 16-week intervention in the form of aerobic, stretch, and skills workouts. ${ }^{40}$ Nouchi et al also confirmed the above results by a combined 4-week intervention consisting of aerobic, strength, and stretch workouts. $^{41}$ Therefore, considering the fact that these findings are consistent with those of the present study, it seems that a combination of physical and cognitive activities can play an important role in achieving the study objectives, which requires further investigation. All physical exercises share one common aspect in their essence; that is, incorporating bodily activities. But since each of these exercises influences an aspect of cognitive performance, it is suggested that a combination of exercises be incorporated. 
Despite all the physical and mental benefits mentioned here, lack of motion is prevalent among the elderly. ${ }^{42}$ Nadri et al assert that the most important factors motivating the elderly to participate in physical and sports activities are gaining health, retaining and improving fitness, joy and pleasure, social interactions, and stress control. ${ }^{22}$ The physical games in the present study have realized the study hypotheses by providing the same motivators. Finch's study also confirmed this, and found that a game-oriented intervention plays an important role in this regard. ${ }^{43}$ In a 1-month intervention, by designing a board game and inducing excitement, Mouton et al observed that even at 3 months after the completion of the program, motion and activities among the elderly subjects maintained the increase seen during the study, and the objectives, such as improvements in balance and ankle strength, had been attained. ${ }^{25}$ Zach and Shalom carried out a comparison between three types of intervention, namely volleyball, stretch, and aerobic workouts, on subjects aged $<50$ years, and concluded that the working memory in all three groups had improved, with the highest improvement observed in the game group. ${ }^{44}$ This improvement in working memory was seen in the present study too. Kramer and Erickson showed that even relatively short exercises prevented brain volume reduction in the elderly, and active individuals had increased gray matter in their prefrontal cortex. $^{45}$ This may support the significant changes observed in the present study. It seems that carrying out the interventions in the form of games and joyful sports acts as a motivator that increases the participation of the elderly in the event, which will, in turn, contribute to preventing a lot of impairments that can arise from a lack of movement, including cognitive disorders.

\section{Limitations}

Findings from this study should be considered in view of its limitations:

- Despite all the efforts made on the part of the researcher in picking totally prepared patients and in careful filling out of the questionnaires, it should still be considered that the elderly who filled them out may not have had enough focus for accuracy.

- At the beginning of the research, the dissatisfaction of the elderly with a previous researcher caused problems in their participation in the centers.
- To prove the assumption that the nature of the game excited people, we needed another group to intervene with exercise and to compare the groups.

- In this study, the researchers did not take into account the current exercise levels through the ADL of individuals, which could affect the results.

- One of the most important limitations was the responsibility of the first author in administering all questionnaires, and especially in implementing the post-intervention interview, which could influence the assessment process in some way.

- The lack of random assignment and the small groups may affect the results.

- Participants in the post-intervention assessment were probably more motivated because of attending the physical games, and they may have been more engaged than the control group in answering the questionnaires.

- The coincidence of two deaths occurring in the control group at the time of the study led to a decrease in collaboration by the elderly.

- Among other limitations in the study were the lack of studies in this area, the study's taking place during the hot season, and the limited number of subjects.

- Since the results were based on a limited number of subjects at one adult day-care center, one should take care in the interpretation and generalization of the results.

- Still, these findings are substantial and should encourage further studies on a larger scale, as one of the limitations in this program was the lack of studies in the field of physical games among the elderly, and most of the past studies related only to computer games.

\section{Conclusion}

The results of this study confirm the effect of physical activity on improvements in cognitive performance. But the challenge here is that the elderly lack the required level of activity or movement. This study made use of the role of games in creating motivation for movement among the elderly, so much so that they gradually started to participate in the sessions with more interest and enthusiasm. Even those elderly who lacked the ability to play the games would show up at the playground to watch and cheer the participants on. Being unrestricted by transportation needs and costs, witnessing positive results within a short period, being in the open air, having the chance 
to perform, and getting to interact with other age groups were among the strengths of this program.

\section{Acknowledgments}

This study is the result of the research program from the Master's thesis approved by the Babol University of Medical Sciences in June 25, 2017 with the Ethics Code 1396-24, and sponsored by the research department of the university. We would like to extend our thanks to the officials of the university, the day-care centers of Hamrah Salamat in Babol and Javidan in Amol, the dear elderly people at these two facilities, and everyone else who cooperated with us in this study.

\section{Disclosure}

The authors report no conflicts of interest in this work.

\section{References}

1. Lunenfeld B. The ageing male: demographics and challenges. World J Urol. 2002;20(1):11-16.

2. Mirzaie M, Darabi S. Population aging in Iran and rising health care costs. Iran J Ageing. 2017;12(2):156-169.

3. Rafizadeh N. Reflection on the active and effective role of day care centers for the elderly with the comparative approach of iran and the united States. Mohandesiy-e Sakhteman Va oloom-e Maskan. 2013;9(19):58-65.

4. Callahan S Knowledge and attitudes about aging: a study of undergraduate students at the university of north carolina at charlotte. 20 2011; Available from: http://gerontology uncc edu/sites/gerontology uncc edu/files/media/abstracts/Knowledge $\%$ 20and\% 20Attitudes. Accessed September, 2018.

5. Dev MK, Paudel N, Joshi ND, Shah DN, Subba S. Psycho-Social Impact of Visual Impairment on Health-Related Quality of Life among Nursing Home Residents. BMC Health Services Research: 2014;3.

6. GhazanfariI F, Hashemi S, Sepahvand R. The survey for relation between cognitive status and life quality in older people at army retired community in Khorramabaad 2011. faslnameh pezeshk $v$ parastar dar razm. 2013;(21-22):11-17.

7. Craik FI, Salthouse TA. The Handbook of Aging and Cognition. New York: Psychology Press; 2011.

8. Caracciolo B, Palmer K, Monastero R, Winblad B, Bäckman L, Fratiglioni L. Occurrence of cognitive impairment and dementia in the community A 9-year-long prospective study. Neurology. 2008;70 (19 Part 2):1778-1785. doi:10.1212/01.wnl.0000288180.21984.cb

9. Busse A, Bischkopf J, Riedel-Heller SG, Angermeyer MC. Mild cognitive impairment: prevalence and incidence according to different diagnostic criteria: results of the Leipzig Longitudinal Study of the Aged (LEILA75+). B J Psych. 2003;182(5):449-454.

10. Unverzagt FW, Ogunniyi A, Taler V, et al. Incidence and risk factors for cognitive impairment no dementia and mild cognitive impairment in African Americans. Alzheimer Dis Assoc Disord. 2011;25(1):4. doi:10.1097/WAD.0b013e3181f1c8b1

11. Kheirkhah F, Hosseini SR, Fallah R, Bijani, A. Prevalence of cognitive disorders in elderly people of Amirkola (2011-2012). Iran J Psych Clin Psychol. 2014;19(4):247-254.

12. Park MH. Informant questionnaire on cognitive decline in the elderly (IQCODE) for classifying cognitive dysfunction as cognitively normal, mild cognitive impairment, and dementia. Int Psychogeriatr. 2017;29(9):1461-1467. doi:10.1017/S1041610217000965
13. Nahid S, Hassan K, Maryam N, Mokhtari P. The effect of physical activity on the memory of women aged 50-70 with memory impairment. New Cell Mol Biotechnol. 2013;3(11):47-54.

14. Erickson KI, Gildengers AG, Butters MA. Physical activity and brain plasticity in late adulthood. Dialogues Clin Neurosci. 2013;15(1):99.

15. Angevaren M, Aufdemkampe G, Verhaar H, Aleman A, Vanhees L. Physical activity and enhanced fitness to improve cognitive function in older people without known cognitive impairment. Cochrane Database Syst Rev. 2008;3:3.

16. Rovio S, Kåreholt I, Helkala E-L, et al. Leisure-time physical activity at midlife and the risk of dementia and Alzheimer's disease. Lancet Neurol. 2005;4(11):705-711. doi:10.1016/S1474-4422(05)70198-8

17. Cooper R, Kuh D, Cooper C, et al. Objective measures of physical capability and subsequent health: a systematic review. Age Ageing. 2010;40(1):14-23. doi:10.1093/ageing/afq117

18. Law LL, Barnett F, Yau MK, Gray MA. Effects of combined cognitive and exercise interventions on cognition in older adults with and without cognitive impairment: a systematic review. Ageing Res Rev. 2014;15:61-75. doi:10.1016/j.arr.2014.02.008

19. Busse AL, Gil G, Santarém JM, Jacob Filho W. Physical activity and cognition in the elderly: a review. Dement Neuropsychol. 2009;3 (3):204-208. doi:10.1590/S1980-57642009DN30300005

20. Chang EC-H, Chu C-H, Karageorghis CI, et al. Relationship between mode of sport training and general cognitive performance. J Sport Health Sci. 2017;6(1):89-95. doi:10.1016/j.jshs.2015.07.007

21. Mardomi K, Sima E. Gameplay and environment design strategy. Iran Archit Urbanism. 2014;7:65-74.

22. Nadri A, Safania AM, Amritash AM. Determinant of the implementation of physical activities in elderly in Tehran. J Gerontol. 2016;1 (2):66-79. doi:10.18869/acadpub.joge.1.2.66

23. Eshaghi SR, Shahsanai A, Ardakani MM. Assessment of the physical activity of elderly population of Isfahan, Iran. J Isfahan Med Schl. 2011;29:147.

24. Motefaker M, Sadrbafghi S, Rafiee M, et al. SuicEpidemiology of physical activity: a population based study in Yazd cityide attempt and its relation to stressors and supportive systems: a study in Karaj city. Tehran Univ Med J TUMS Publ. 2007;65(4):77-81.

25. Mouton A, Gillet N, Mouton F, et al. Effects of a giant exercising board game intervention on ambulatory physical activity among nursing home residents: a preliminary study. Clin Interv Aging. 2017;12:847. doi:10.2147/CIA.S134760

26. Howes SC, Charles DK, Marley J, Pedlow K, McDonough SM. Gaming for health: systematic review and meta-analysis of the physical and cognitive effects of active computer gaming in older adults. Phys Ther. 2017;97(12):1122-1137. doi:10.1093/ptj/pzx088

27. Hayat Pouya(dynamic yard)instructions. In: ministry of education dopeah, editor. Tehran, Iran: Ministry of Education; 2013.

28. Taheri Tanjani P, Azadbakht M. Psychometric properties of the persian version of the activities of daily living scale and instrumental activities of daily living scale in elderly. J Mazandaran Uni Med Sci. 2016;25(132):103-112.

29. Foroughan M, Wahlund L-O, Jafari Z, Rahgozar M, Farahani IG, Rashedi V. Validity and reliability of Abbreviated Mental Test Score (AMTS) among older Iranian. Off J Jpn Psychogeriatr Soc. 2017;17 (6):460-465. doi:10.1111/psyg.12276

30. Groth-Marnat G. Handbook of Psychological Assessment. NJ, USA: John Wiley \& Sons; 2009.

31. Orangi M, Atefvahid MK, Ashayeri H. Standardization of the Revised Wechsler Memory Scale in Shiraz. Iran J Psych Clin Psychol. 2002;7(4):56-66.

32. de Asteasu MLS, Martínez-Velilla N, Zambom-Ferraresi F, CasasHerrero Á, Izquierdo M. Role of physical exercise on cognitive function in healthy older adults: a systematic review of randomized clinical trials. Ageing Res Rev. 2017;37:117-134. doi:10.1016/j. arr.2017.05.007 
33. Zhu $\mathrm{X}$, Yin S, Lang M, He R, Li J. The more the better? A meta-analysis on effects of combined cognitive and physical intervention on cognition in healthy older adults. Ageing Res Rev. 2016;31:67-79. doi:10.1016/j.arr.2016.07.003

34. Legault C, Jennings JM, Katula JA, et al. Designing clinical trials for assessing the effects of cognitive training and physical activity interventions on cognitive outcomes: the Seniors Health and Activity Research Program Pilot (SHARP-P) study, a randomized controlled trial. BMC Geriatr. 2011;11(1):27. doi:10.1186/14712318-11-27

35. Barnes DE, Santos-Modesitt W, Poelke G, et al. The mental activity and eXercise (MAX) trial: a randomized controlled trial to enhance cognitive function in older adults. JAMA Intern Med. 2013;173 (9):797-804. doi:10.1001/jamainternmed.2013.189

36. Broe G, Creasey H, Jorm A, et al. Health habits and risk of cognitive impairment and dementia in old age: a prospective study on the effects of exercise, smoking and alcohol consumption. Aust N Z J Public Health. 1998;22(5):621-623.

37. Iuliano E, Di Cagno A, Aquino G, et al. Effects of different types of physical activity on the cognitive functions and attention in older people: a randomized controlled study. Exp Gerontol. 2015;70:105-110. doi:10.1016/j.exger.2015.07.008

38. Movahedi A, Rajabi H, Rezvani BE. Comparison of the Effectiveness of aaerobic versus pilates training on cognitive function of elderly females. J Mot Behav. 2016;8(25):29-46.
39. Eggenberger P, Schumacher V, Angst M, Theill N, de Bruin ED. Does multicomponent physical exercise with simultaneous cognitive training boost cognitive performance in older adults? A 6-month randomized controlled trial with a 1-year follow-up. Clin Interv Aging. 2015;10:1335.

40. Vaughan S, Wallis M, Polit D, Steele M, Shum D, Morris N. The effects of multimodal exercise on cognitive and physical functioning and brain-derived neurotrophic factor in older women: a randomised controlled trial. Age Ageing. 2014;43(5):623-629. doi:10.1093/ageing/afu010

41. Nouchi R, Taki Y, Takeuchi H, et al. Four weeks of combination exercise training improved executive functions, episodic memory, and processing speed in healthy elderly people. Age. 2014;36:787-799. doi:10.1007/s11357-013-9588-x

42. Silveira D, Siqueira F, Teixeira A, et al. Leisure time physical activity in elderly users of primary health units in Brazil. J Sci Med Sport. 2012;15:S291. doi:10.1016/j.jsams.2012.11.708

43. Finch H. Physical Activity" at Our Age”: qualitative Research among People over the Age of 50. London: Health Education Authority; 1997.

44. Zach S, Shalom E. The influence of acute physical activity on working memory. Percept Mot Skills. 2016;122(2):365-374. doi:10.1177/ 0031512516631066

45. Kramer AF, Erickson KI. Effects of physical activity on cognition, well-being, and brain: human interventions. Alzheimer's Dementia. 2007;3(2):S45-S51. doi:10.1016/j.jalz.2007.01.008
Clinical Interventions in Aging

\section{Publish your work in this journal}

Clinical Interventions in Aging is an international, peer-reviewed journal focusing on evidence-based reports on the value or lack thereof of treatments intended to prevent or delay the onset of maladaptive correlates of aging in human beings. This journal is indexed on PubMed Central, MedLine, CAS, Scopus and the Elsevier

\section{Dovepress}

Bibliographic databases. The manuscript management system is completely online and includes a very quick and fair peer-review system, which is all easy to use. Visit http://www.dovepress.com/ testimonials.php to read real quotes from published authors. 